Article

\title{
Study on the Prevalence of Severe Anemia among Non-Pregnant Women of Reproductive Age in Rural China: A Large Population-Based Cross-Sectional Study
}

\author{
Qiuyue Ma ${ }^{1}$, Shikun Zhang ${ }^{2}$, Jue Liu ${ }^{1}$, Qiaomei Wang ${ }^{2}$, Haiping Shen ${ }^{2}$, Yiping Zhang ${ }^{2}$ \\ and Min Liu ${ }^{1, *}$ \\ 1 Department of Epidemiology and Biostatistics, School of Public Health, Peking University, \\ 100191 Beijing, China; mqyue10@163.com (Q.M.); liujue7@163.com (J.L.) \\ 2 Department of Maternal and Child Health, National Health and Family Planning Commission of the PRC, \\ 100190 Beijing, China; shikun_zhang1121@163.com (S.Z.); qiaomei_w@163.com (Q.W.); \\ shenhaiping68@126.com (H.S.); yiping791129@126.com (Y.Z.) \\ * Correspondence: liumin@bjmu.edu.cn; Tel.: +86-10-8280-5146
}

Received: 1 November 2017; Accepted: 27 November 2017; Published: 28 November 2017

\begin{abstract}
Globally, severe anemia impacts millions of non-pregnant women. However, studies on the prevalence of severe anemia through large epidemiologic surveys among non-pregnant women have been scarce in China. In this study, we aimed to study the prevalence of severe anemia and its determinants among non-pregnant women living in rural areas of China. Data were gathered for 712,101 non-pregnant women aged between 21 and 49 years who attended the 2012 National Free Preconception Health Examination Project. Severe anemia in non-pregnant women was defined as a hemoglobin $(\mathrm{Hb})$ concentration lower than $80 \mathrm{~g} / \mathrm{L}$. Associated factors were analyzed using univariate and multivariate logistic regression methods. Out of the 712,101 non-pregnant women living in the rural areas of China, 1728 suffered from severe anemia, with a prevalence of $0.24 \%$ (95\% confidence interval (CI): $0.23-0.25 \%$ ). Results from the multivariable logistic regression showed that elderly (adjusted odds ratio $(\mathrm{aOR})=3.08)$, living in the northwest region $(\mathrm{aOR}=2.88)$, having a history of anemia $(\mathrm{aOR}=5.76)$, with heavy menstrual blood loss ( $\mathrm{aOR}=1.84$ ), and with a history of using an intra-uterine device $(\mathrm{aOR}=1.47)$ etc., were independent determinants for women with severe anemia in rural China. The prevalence of severe anemia among Chinese non-pregnant women living in the rural areas was lower than the reported global prevalence. Prevention and intervention programs for severe anemia are required among non-pregnant women of reproductive age in the rural areas of China.
\end{abstract}

Keywords: severe anemia; prevalence; non-pregnant women; China; rural areas

\section{Introduction}

Anemia is of public health concern that affects countries with low, middle, or high income [1]. It is especially prevalent in women of reproductive age [2]. Anemia is defined as a low blood hemoglobin $(\mathrm{Hb})$ concentration. The causes of anemia include iron and other micronutrient deficiencies, acute and chronic infections, inherited or acquired disorders, etc. [1]. Patients with anemia present similar clinical symptoms such as fatigue, breathlessness, dizziness, and headache [3]. Anemia also increases the susceptibility to different kinds of infections and impairs the work capacity [4]. Severity of symptom caused by anemia is paralleled with the severity of anemia [5]. Severe anemia may predispose to infection and heart failure [6], while severe anemia during pregnancy may significantly contribute to both maternal mortality and morbidity [7]. Severe maternal anemia carries a significant risk of hemorrhage and infection in mothers [8], reduces the resistance to blood loss causing maternal death [2], 
and place women at higher risk of death during delivery and the period following childbirth [9]. Maternal anemia may also increase the risk of adverse pregnancy outcomes, such as preterm birth, low birth weight, small size for gestational age infants, perinatal death, and anemia in infancy [10-14].

Most of the previous studies were focused on the prevalence and determinants of anemia among pregnant women $[3,6,12]$, but few examined severe anemia prevalence in non-pregnant women. The World Health Organization (WHO) reported that $58 \%$ of the pregnant women with anemia were also anemic before being pregnant [2]. Anemia appeared as an important public health problem throughout the world, particularly in developing countries $[15,16]$. Globally, the overall prevalence of severe anemia among non-pregnant women of reproductive age was $1.1 \%$, affecting 19 million non-pregnant women [13]. Prevention of anemia in non-pregnant women could improve the health status of the pregnant women, eventually contributing to the reduction of both maternal and perinatal mortality.

As a developing country, China should pay greater attention to severe anemia in Chinese women of reproductive age. According to a WHO report in 2011, the prevalence of severe anemia among Chinese non-pregnant women was $0.3 \%$, lower than both the global prevalence $(1.1 \%)$ and the prevalence in Asia (1.3\%) [1]. However, there were few studies assessing the prevalence of severe anemia among non-pregnant women in the country, and most of the criteria they used were different from the ones recommended by WHO (Hb concentration lower than $80 \mathrm{~g} / \mathrm{L}$ [17]). Only one study followed the WHO criteria, which was conducted among non-pregnant and not breastfeeding women in 1998, covering 11 provinces of China, showing the prevalence of severe anemia as $2.1 \%$ [18]. No large population-based study focusing on the prevalence of severe anemia among Chinese reproductive age women have been carried out in recent years.

In this study, the original data we used was from the 2012 National Free Preconception Health Examination Project (NFPHEP). The criteria we used to estimate the prevalence of severe anemia in Chinese rural non-pregnant women was following WHO recommendation. In this paper, the estimated prevalence on severe anemia prevalence among non-pregnant women of reproductive age in rural China had been updated.

\section{Materials and Methods}

\subsection{Study Design}

This was a population-based cross-sectional study in which involved 712,101 non-pregnant women aged 21-49 years who attended the NFPHEP between 1 January 2012 and 31 December 2012. Participants were from 193 counties in 30 provinces; from all over the country. All the participants were given written informed consent forms before enrollment. Data regarding the $\mathrm{Hb}$ concentration was obtained from the laboratory tests. Hb concentration was measured using the cyanomethemoglobin method by trained medical staff. A standardized questionnaire was used by local health workers to collect data on demographic characteristics (including age; education levels; occupation; ethnic origins and address of residence). Histories on using contraceptive methods and reproduction (including histories on using intra-uterine devices (IUD) pregnancy; miscarriages and the number of pregnancies); health status (including history of anemia; menstrual blood loss; body mass index (BMI)); and meat and egg eating habits of the participants were also collected. Both detailed design and quality assessment on NFPHEP were stated in other articles elsewhere $[19,20]$.

In the questionnaire, we asked the participants about their nutritional behavior, whether they ate meat and eggs in their regular lives. If the answer was "yes", we then considered they were meat and egg eaters. During the physical examinations, measurements of height and weight of participants were performed by qualified and trained physicians. BMI was calculated as weight in kilograms divided by height in meters squared $\left(\mathrm{kg} / \mathrm{m}^{2}\right)$.

According to the administrative divisions, the 30 provinces were divided into six regions, as follows: north region (including Beijing, Tianjin, Hebei, Shanxi, Inner Mongolia), northeast region (including Liaoning, Jilin, Heilongjiang), east region (including Shanghai, Jiangsu, Zhejiang, Anhui, 
Fujian, Jiangxi, Shandong), central south region (including Henan, Hubei, Hunan, Guangdong, Guangxi, Hainan), southwest region (including Chongqing, Sichuan, Guizhou, Yunnan), and northwest region (including Shaanxi, Gansu, Qinghai, Ningxia, Xinjiang). According to the age distributions, the participants were divided into six groups as follows: 21-24 years, 25-29 years, 30-34 years, 35-39 years, 40-44 years, and 45-49 years old. Again, according to the education levels, the participants were divided into four groups as follows: primary school or below, junior high school, senior high school, and college or higher. Other groupings would include: occupation (farmers, workers, and others), ethnic origin (Han and others), self-reported menstrual blood loss (minor, medium, or heavy), BMI (lower than 18.5, 18.5-24, higher than 24$)$, and number of pregnancies $(0,1, \geq 2)$.

\subsection{Case Definition of Severe Anemia}

We followed the definition of severe anemia as the thresholds for $\mathrm{Hb}$ concentration of non-pregnant women as lower than $80 \mathrm{~g} / \mathrm{L}$ [17], recommended by the WHO. We also adjusted the thresholds for altitude since it was related to $\mathrm{Hb}$ concentration. Adjustments of severe anemia thresholds for people living at altitudes higher than $1000 \mathrm{~m}$ were recommended by the WHO: thresholds plus $2 \mathrm{~g} / \mathrm{L}$ for people living at altitudes between $1000 \mathrm{~m}$ and $1500 \mathrm{~m}$; plus $5 \mathrm{~g} / \mathrm{L}$ for those living at altitudes between $1500 \mathrm{~m}$ and $2000 \mathrm{~m}$; plus $8 \mathrm{~g} / \mathrm{L}$ at $2000-2500 \mathrm{~m}$; plus $13 \mathrm{~g} / \mathrm{L}$ at 2500-3000 m; plus $19 \mathrm{~g} / \mathrm{L}$ at $3000-3500 \mathrm{~m}$; plus $27 \mathrm{~g} / \mathrm{L}$ at $3500-4000 \mathrm{~m} ; 35 \mathrm{~g} / \mathrm{L}$ at $4000-4500 \mathrm{~m}$; and plus $45 \mathrm{~g} / \mathrm{L}$ at altitudes higher than $4500 \mathrm{~m}$ [17].

\subsection{Methods Used for Statistical Analysis}

Proportions were used to describe data related to demographic characteristics, contraceptive method, reproduction, and the health status of the participants. The prevalence of severe anemia was estimated using the percentage and $95 \%$ confidence interval (CI). Univariate and multivariate logistic regression methods were used to analyze determinants related to severe anemia. Data was analyzed under the stratification of the histories of using IUD and pregnancy. Analysis by the number of pregnancies was also performed. We considered two-tailed $p$ values of lower than 0.05 to be statistically significant. All methods used for analyses were performed with SPSS Statistics for Windows, Version 19 (IBM Corp, Armonk, NY, USA).

\subsection{Ethical Approval}

All subjects gave their informed consent for inclusion before they participated in the study. The study was conducted in accordance with the Declaration of Helsinki, and the study was approved by Institutional Review Board of Chinese Association of Maternal and Child Health Studies (Project identification code AMCHS-2014-6).

\section{Results}

The mean age of all women who participated in this study was $27.37 \pm 4.66$ years. Demographic characteristics of the participants are as follows: 532,246 (74.74\%) were between 21 and 29 years; $475,660(66.79 \%)$ had an education level of junior high school or below; 518,803 (72.86\%) were farmers; $640,820(89.99 \%)$ were of Han ethnicity; and 246,735 (34.65\%) were from the central south region (Table 1). 
Table 1. Demographic characteristics and severe anemia prevalence among non-pregnant women of reproductive age in 2012, rural China.

\begin{tabular}{|c|c|c|c|c|c|c|}
\hline & Number & $\%$ & Severe Anemia $(n)$ & Prevalence of Severe Anemia $(\%(95 \% \mathrm{CI}))$ & cOR $(95 \% \mathrm{CI})$ & $\mathrm{aOR}^{\mathrm{a}}(95 \% \mathrm{CI})$ \\
\hline All participants & 712,101 & 100.00 & 1728 & $0.24(0.23-0.25)$ & - & - \\
\hline \multicolumn{7}{|l|}{ Age group, years } \\
\hline $21-24$ & 216,573 & 30.41 & 448 & $0.21(0.19-0.23)$ & 1.00 & 1.00 \\
\hline $25-29$ & 315,673 & 44.33 & 636 & $0.20(0.19-0.22)$ & $0.97(0.86-1.10)$ & $0.94(0.82-1.07)$ \\
\hline $30-34$ & 120,336 & 16.90 & 372 & $0.31(0.28-0.34)$ & $1.50(1.30-1.72)$ & $1.19(1.02-1.38)$ \\
\hline $35-39$ & 40,199 & 5.65 & 141 & $0.35(0.29-0.41)$ & $1.70(1.41-2.05)$ & $1.10(0.89-1.36)$ \\
\hline $40-44$ & 16,155 & 2.27 & 102 & $0.63(0.51-0.75)$ & $3.07(2.47-3.80)$ & $2.16(1.71-2.73)$ \\
\hline $45-49$ & 3165 & 0.44 & 29 & $0.92(0.58-1.25)$ & $4.46(3.06-6.51)$ & $3.08(2.07-4.60)$ \\
\hline \multicolumn{7}{|l|}{ Education } \\
\hline Primary school or below & 31,150 & 4.37 & 140 & $0.45(0.38-0.52)$ & 1.00 & 1.00 \\
\hline Junior high school & 444,510 & 62.42 & 1287 & $0.29(0.27-0.31)$ & $0.64(0.54-0.77)$ & $0.78(0.65-0.94)$ \\
\hline Senior high school & 131,986 & 18.53 & 192 & $0.15(0.12-0.17)$ & $0.32(0.26-0.40)$ & $0.54(0.43-0.69)$ \\
\hline College or higher & 92,826 & 13.04 & 94 & $0.10(0.08-0.12)$ & $0.23(0.17-0.29)$ & $0.43(0.32-0.58)$ \\
\hline Not available & 11,629 & 1.63 & - & - & - & - \\
\hline \multicolumn{7}{|l|}{ Occupation } \\
\hline Farmers & 518,803 & 72.86 & 1473 & $0.28(0.27-0.30)$ & 1.00 & 1.00 \\
\hline Workers & 64,527 & 9.06 & 88 & $0.14(0.11-0.16)$ & $0.48(0.39-0.60)$ & $0.65(0.52-0.82)$ \\
\hline Others & 113,606 & 15.95 & 149 & $0.13(0.11-0.15)$ & $0.46(0.39-0.55)$ & $0.76(0.62-0.93)$ \\
\hline Not available & 15,165 & 2.13 & - & - & - & - \\
\hline \multicolumn{7}{|l|}{ Ethnic origin } \\
\hline Han & 640,820 & 89.99 & 1425 & $0.22(0.21-0.23)$ & 1.00 & 1.00 \\
\hline Others & 62,262 & 8.74 & 293 & $0.47(0.42-0.52)$ & $2.12(1.87-2.41)$ & $1.28(1.11-1.49)$ \\
\hline Not available & 9019 & 1.27 & - & - & - & - \\
\hline \multicolumn{7}{|l|}{ Region } \\
\hline Southwest & 92,598 & 13.00 & 157 & $0.17(0.14-0.20)$ & 1.00 & 1.00 \\
\hline Central south & 246,735 & 34.65 & 382 & $0.15(0.14-0.17)$ & $0.91(0.76-1.10)$ & $1.16(0.95-1.42)$ \\
\hline North & 87,890 & 12.34 & 220 & $0.25(0.22-0.28)$ & $1.48(1.20-1.81)$ & $1.65(1.32-2.06)$ \\
\hline Northeast & 47,767 & 6.71 & 153 & $0.32(0.27-0.37)$ & $1.89(1.51-2.36)$ & $1.81(1.42-2.30)$ \\
\hline East & 151,866 & 21.33 & 381 & $0.25(0.23-0.28)$ & $1.48(1.23-1.78)$ & $1.84(1.51-2.26)$ \\
\hline Northwest & 85,245 & 11.97 & 435 & $0.51(0.46-0.56)$ & $3.02(2.52-3.63)$ & $2.88(2.37-3.51)$ \\
\hline
\end{tabular}

a Adjusted for age, education, occupation, ethnic origin, region, history of using intra-uterine device (IUD), histories on pregnancy or miscarriage, history on anemia, menstrual blood loss,

body mass index (BMI), and meat and egg eating habits. CI: confidence interval; cOR: crude odds ratio; aOR: adjusted odds ratio. 
Of the 712,101 non-pregnant women, 1728 suffered severe anemia, with a prevalence of $0.24 \%$ (95\% CI: $0.23-0.25 \%)$. The prevalence was significantly higher in those $45-49$ years old $(0.92 \%)$ than in other age groups $(0.20-0.63 \%)$. The prevalence of severe anemia was significantly lower in women with education levels of junior high school $(0.29 \%)$, senior high school $(0.15 \%)$, college or higher $(0.10 \%)$, but appeared the highest in women who only received primary or even less education $(0.45 \%)$. The prevalence seen in farmers $(0.28 \%)$ was significantly higher than in workers $(0.14 \%)$ or in other occupations $(0.13 \%)$. The prevalence of women with other ethnic origins $(0.47 \%)$ was significantly higher than those in Han Chinese $(0.22 \%)$. Women who lived in the northwest region had the highest prevalence $(0.51 \%)$ than those living in other regions $(0.15-0.32 \%$, Table 1$)$.

The prevalence rates of women appeared higher among those with history of using IUD $(0.49 \%)$ and pregnancy $(0.34 \%)$ than those without $(0.20 \%, 0.16 \%$, respectively). The prevalence of women with the history of miscarriage $(0.27 \%)$ was higher than those without $(0.24 \%)$, but with no significant difference. Women having had a history of anemia showed significantly higher prevalence than those without $(1.09 \%, 0.23 \%$, respectively). Compared with groups under minor or medium menstrual blood loss, the prevalence of severe anemia in women with heavy menstrual blood loss appeared significantly higher. Women who had a BMI between 18.5 and 24, or enjoyed eating meat and eggs, had higher prevalence than those in other opposite groups, but with no significant differences (Table 2).

Through multivariate logistic regression analysis, factors as: being elderly ( $\mathrm{aOR}=3.08)$, being other ethnicities $(\mathrm{aOR}=1.28)$, living in the northwest regions ( $\mathrm{aOR}=2.88)$, histories of using IUD $(\mathrm{aOR}=1.47)$, pregnancy $(\mathrm{aOR}=1.38)$, anemia $(\mathrm{aOR}=5.76)$, and heavy menstrual blood loss $(\mathrm{aOR}=1.84)$, etc., were all associated with the prevalence of severe anemia. Women aged $45-49$ years were more likely to have severe anemia than women aged $21-24$ years $(\mathrm{aOR}=3.08,95 \% \mathrm{CI}: 2.06-4.60)$. Women with education levels of primary school or lower and farmers had higher risks of having severe anemia. Women of other ethnicities were 1.28 times more likely of having severe anemia than those of Han ethnicity. Compared to the southwest region, women who lived in the northwest region were more likely to be severely anemic ( $\mathrm{aOR}=2.88,95 \% \mathrm{CI}$ : 2.37-3.51). A history of using IUD or being pregnant increased the risk of suffering severe anemia by 1.47 and 1.38 times, respectively. A history of miscarriage showed an inverse relationship with severe anemia $(\mathrm{aOR}=0.85,95 \% \mathrm{CI}$ : 0.74-0.98). A history of ever being anemic increased the risk of severe anemia by 5.76 times. Women with heavy menstrual blood loss were 1.84 times more likely to be severely anemic to women with only minor blood loss. The risk of severe anemia in women who had a BMI $\geq 24$ was $24 \%$ lower, compared to women who had a BMI below 18.5. In our study, meat and egg eating habits did not seem to be linked to the increased risk of severe anemia (Tables 1 and 2). 
Table 2. Histories on using contraceptive methods, reproduction, health status, and severe anemia prevalence among non-pregnant women of reproductive age in 2012, rural China.

\begin{tabular}{|c|c|c|c|c|c|c|}
\hline & Number & $\%$ & Severe Anemia $(n)$ & Prevalence of Severe Anemia (\% (95\% CI)) & cOR $(95 \% \mathrm{CI})$ & $\mathrm{aOR}^{\mathrm{a}}(95 \% \mathrm{CI})$ \\
\hline All participants & 712,101 & 100.00 & 1728 & $0.24(0.23-0.25)$ & - & - \\
\hline \multicolumn{7}{|c|}{ History of using IUD } \\
\hline No & 601,121 & 84.42 & 1186 & $0.20(0.19-0.21)$ & 1.00 & 1.00 \\
\hline Yes & 110,980 & 15.58 & 542 & $0.49(0.45-0.53)$ & $2.48(2.24-2.75)$ & $1.47(1.30-1.67)$ \\
\hline \multicolumn{7}{|c|}{ History on pregnancy } \\
\hline No & 388,597 & 54.57 & 628 & $0.16(0.15-0.17)$ & 1.00 & 1.00 \\
\hline Yes & 319,189 & 44.82 & 1096 & $0.34(0.32-0.36)$ & $2.13(1.93-2.35)$ & $1.38(1.21-1.59)$ \\
\hline Not available & 4315 & 0.61 & - & - & - & - \\
\hline \multicolumn{7}{|c|}{ History on miscarriage } \\
\hline No & 598,045 & 83.98 & 1424 & $0.24(0.23-0.25)$ & 1.00 & 1.00 \\
\hline Yes & 114,056 & 16.02 & 304 & $0.27(0.24-0.30)$ & $1.12(0.99-1.27)$ & $0.85(0.74-0.98)$ \\
\hline \multicolumn{7}{|c|}{ History on anemia } \\
\hline No & 703,399 & 98.78 & 1633 & $0.23(0.22-0.24)$ & 1.00 & 1.00 \\
\hline Yes & 8702 & 1.22 & 95 & $1.09(0.87-1.31)$ & $4.74(3.85-5.84)$ & $5.76(4.63-7.18)$ \\
\hline \multicolumn{7}{|c|}{ Menstrual blood loss } \\
\hline Minor & 20,033 & 2.81 & 36 & $0.18(0.12-0.24)$ & 1.00 & 1.00 \\
\hline Medium & 661,682 & 92.92 & 1589 & $0.24(0.23-0.25)$ & $1.34(0.96-1.86)$ & $1.31(0.94-1.83)$ \\
\hline Heavy & 24,023 & 3.37 & 95 & $0.40(0.32-0.47)$ & $2.21(1.50-3.24)$ & $1.84(1.25-2.71)$ \\
\hline Not available & 6363 & 0.89 & - & - & - & - \\
\hline \multicolumn{7}{|l|}{ BMI } \\
\hline$<18.5$ & 77,389 & 10.87 & 170 & $0.22(0.19-0.25)$ & 1.00 & 1.00 \\
\hline $18.5-24$ & 514,707 & 72.28 & 1274 & $0.25(0.23-0.26)$ & $1.13(0.96-1.32)$ & $0.93(0.79-1.09)$ \\
\hline$\geq 24$ & 77,308 & 10.86 & 186 & $0.24(0.21-0.28)$ & $1.10(0.89-1.35)$ & $0.76(0.61-0.94)$ \\
\hline Not available & 42,697 & 6.00 & - & - & - & - \\
\hline \multicolumn{7}{|c|}{ Meat and egg eaters } \\
\hline Yes & 699,519 & 98.23 & 1700 & $0.24(0.23-0.25)$ & 1.00 & 1.00 \\
\hline No & 7379 & 1.04 & 17 & $0.23(0.12-0.34)$ & $0.95(0.59-1.53)$ & $0.82(0.47-1.41)$ \\
\hline Not available & 5203 & 0.73 & _- & - & - & - \\
\hline
\end{tabular}


We analyzed the prevalence of severe anemia stratified by IUD use. Data showed that the distributions of prevalence rates in different age, education level, region of residency, and history of anemia, were similar to the distributions in all women, regardless of having the history of using the IUD. Women with a history of using IUD showed higher prevalence of severe anemia than those without, and the differences were significant in 21-24, 25-29, 30-34, 35-39, and 40-44 year old age groups (Figure 1). Having a history of pregnancy appeared as a determinant for severe anemia in women without the history of using IUD (aOR = 1.39, 95\% CI: 1.19-1.61), but not otherwise. Having a history of miscarriage was not associated with severe anemia in women with a history of using IUD. However, it was a protective factor for women without the history of using IUD (aOR $=0.77,95 \% \mathrm{CI}$ : 0.64-0.93). Women with heavy menstrual blood loss and without the history of using IUD had an increased risk of developing severe anemia (aOR $=1.80,95 \% \mathrm{CI}: 1.14-2.83$, Table 3).

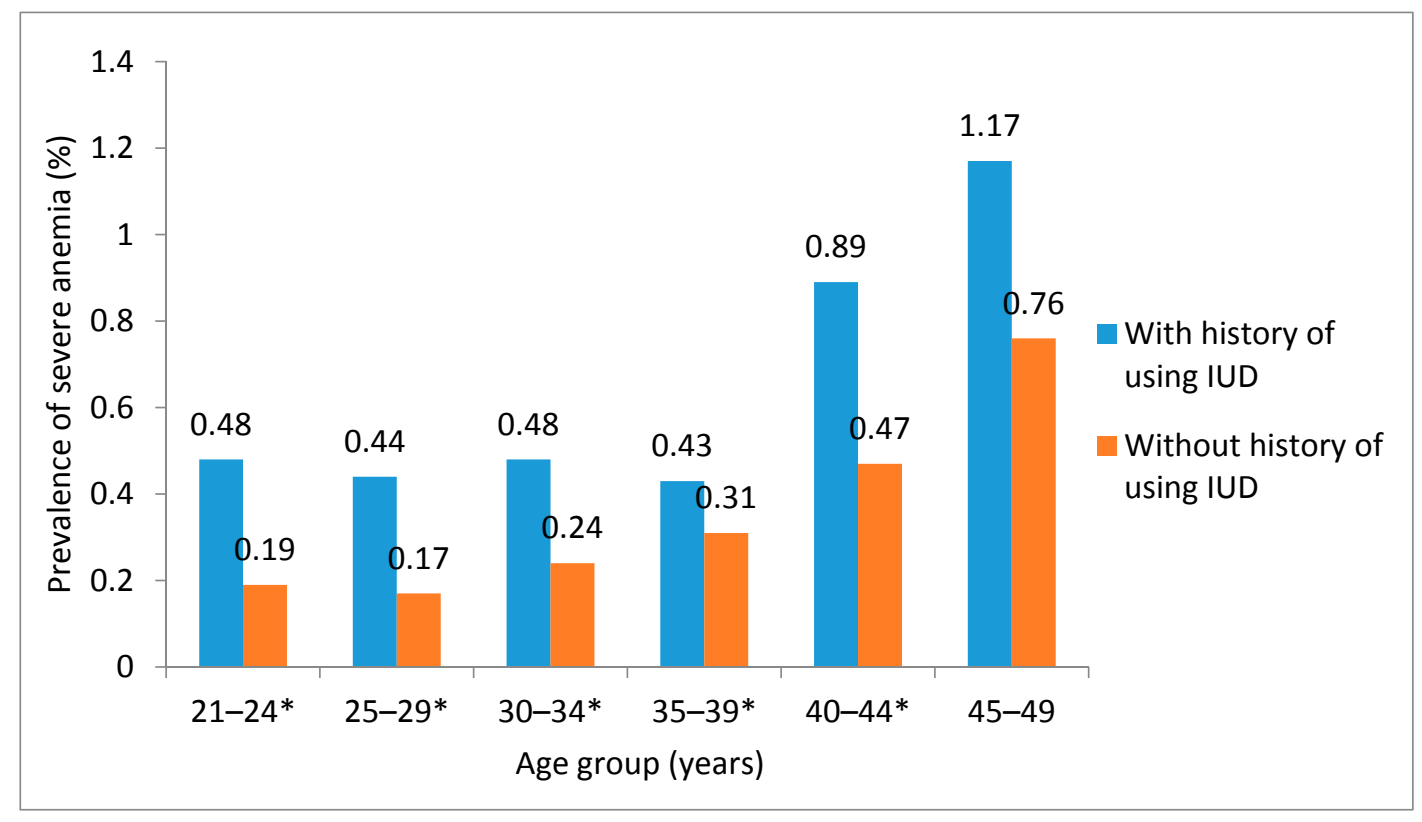

Figure 1. Age-specific prevalence rates of severe anemia in different histories of using intra-uterine device (IUD) in 2012, rural China. * The age group with significant difference in severe anemia prevalence between women with a history of using IUD and those without. 
Table 3. Prevalence of severe anemia among non-pregnant women of reproductive age, stratified by history of using IUD in 2012, rural China.

\begin{tabular}{|c|c|c|c|c|c|c|c|c|}
\hline & \multicolumn{4}{|c|}{ With History of Using IUD } & \multicolumn{4}{|c|}{ Without History of Using IUD } \\
\hline & Number & Severe Anemia, $n$ (\%) & cOR $(95 \% \mathrm{CI})$ & $\mathrm{aOR}^{\mathrm{a}}(95 \% \mathrm{CI})$ & Number & Severe Anemia, $n(\%)$ & cOR $(95 \% \mathrm{CI})$ & $\mathrm{aOR}^{\mathrm{a}}(95 \% \mathrm{CI})$ \\
\hline \multicolumn{9}{|l|}{ Age group, years } \\
\hline $21-24$ & 11,618 & $56(0.48)$ & 1.00 & 1.00 & 204,955 & $392(0.19)$ & 1.00 & 1.00 \\
\hline $25-29$ & 41,879 & $184(0.44)$ & $0.91(0.68-1.23)$ & $1.03(0.75-1.41)$ & 273,794 & $452(0.17)$ & $0.86(0.75-0.99)$ & $0.90(0.78-1.04)$ \\
\hline $30-34$ & 35,262 & $169(0.48)$ & $0.99(0.73-1.35)$ & $1.20(0.87-1.65)$ & 85,074 & $203(0.24)$ & $1.25(1.05-1.48)$ & $1.19(0.99-1.43)$ \\
\hline $35-39$ & 14,733 & $63(0.43)$ & $0.89(0.62-1.27)$ & $0.95(0.64-1.40)$ & 25,466 & $78(0.31)$ & $1.60(1.26-2.05)$ & $1.26(0.96-1.65)$ \\
\hline $40-44$ & 6293 & $56(0.89)$ & $1.85(1.28-2.69)$ & $2.41(1.63-3.57)$ & 9862 & $46(0.47)$ & $2.45(1.80-3.32)$ & $1.90(1.36-2.65)$ \\
\hline $45-49$ & 1195 & $14(1.17)$ & $2.45(1.36-4.41)$ & $2.90(1.55-5.41)$ & 1970 & $15(0.76)$ & $4.00(2.39-6.72)$ & $3.23(1.87-5.56)$ \\
\hline \multicolumn{9}{|l|}{ Education } \\
\hline Primary school or below & 9079 & $66(0.73)$ & 1.00 & 1.00 & 22,071 & $74(0.34)$ & 1.00 & 1.00 \\
\hline Junior high school & 88,897 & $442(0.50)$ & $0.68(0.53-0.89)$ & $0.72(0.55-0.96)$ & 355,613 & $845(0.24)$ & $0.71(0.56-0.90)$ & $0.82(0.63-1.05)$ \\
\hline Senior high school & 9719 & $30(0.31)$ & $0.42(0.27-0.65)$ & $0.53(0.34-0.84)$ & 122,267 & $162(0.13)$ & $0.39(0.30-0.52)$ & $0.56(0.42-0.75)$ \\
\hline College or higher & 2233 & $4(0.18)$ & $0.25(0.09-0.67)$ & $0.32(0.11-0.90)$ & 90,593 & $90(0.10)$ & $0.30(0.22-0.40)$ & $0.46(0.32-0.65)$ \\
\hline \multicolumn{9}{|l|}{ Occupation } \\
\hline Farmers & 99,730 & $508(0.51)$ & 1.00 & 1.00 & 419,073 & $965(0.23)$ & 1.00 & 1.00 \\
\hline Workers & 4799 & $15(0.31)$ & $0.61(0.37,1.02)$ & $0.71(0.42-1.21)$ & 59,728 & $73(0.12)$ & $0.53(0.42-0.67)$ & $0.63(0.49-0.82)$ \\
\hline Others & 5042 & $17(0.34)$ & $0.66(0.41,1.07)$ & $0.89(0.54-1.48)$ & 108,564 & $132(0.12)$ & $0.53(0.44-0.63)$ & $0.73(0.59-0.91)$ \\
\hline \multicolumn{9}{|l|}{ Ethnic origin } \\
\hline Han & 90,262 & $408(0.45)$ & 1.00 & 1.00 & 550,558 & $1017(0.18)$ & 1.00 & 1.00 \\
\hline Others & 20,359 & $134(0.66)$ & $1.46(1.20-1.78)$ & $1.21(0.96-1.54)$ & 41,903 & $159(0.38)$ & $2.06(1.74-2.43)$ & $1.34(1.10-1.62)$ \\
\hline \multicolumn{9}{|l|}{ Region } \\
\hline Southwest & 16,655 & $47(0.28)$ & 1.00 & 1.00 & 75,943 & $110(0.14)$ & 1.00 & 1.00 \\
\hline Central south & 21,128 & $63(0.30)$ & $1.06(0.72-1.54)$ & $1.31(0.87-1.97)$ & 225,607 & $319(0.14)$ & $0.98(0.79-1.21)$ & $1.09(0.86-1.38)$ \\
\hline North & 14,832 & $75(0.51)$ & $1.80(1.25-2.59)$ & $2.34(1.57-3.49)$ & 73,058 & $145(0.20)$ & $1.37(1.07-1.76)$ & $1.40(1.07-1.83)$ \\
\hline Northeast & 11,141 & $69(0.62)$ & $2.20(1.52-3.19)$ & $2.62(1.74-3.94)$ & 36,626 & $84(0.23)$ & $1.59(1.19-2.11)$ & $1.44(1.06-1.96)$ \\
\hline East & 28,914 & $127(0.44)$ & $1.56(1.12-2.18)$ & $2.11(1.45-3.06)$ & 122,952 & $254(0.21)$ & $1.43(1.14-1.79)$ & $1.74(1.37-2.22)$ \\
\hline Northwest & 18,310 & $161(0.88)$ & $3.14(2.26-4.34)$ & $3.41(2.40-4.85)$ & 66,935 & $274(0.41)$ & $2.83(2.27-3.54)$ & $2.66(2.10-3.38)$ \\
\hline \multicolumn{9}{|l|}{ History on pregnancy } \\
\hline No & 2684 & $7(0.26)$ & 1.00 & 1.00 & 385,913 & $621(0.16)$ & 1.00 & 1.00 \\
\hline Yes & 108,223 & $535(0.49)$ & $1.90(0.90-4.01)$ & $1.55(0.73-3.28)$ & 210,966 & $561(0.27)$ & $1.65(1.48-1.86)$ & $1.39(1.19-1.61)$ \\
\hline \multicolumn{9}{|l|}{ History on miscarriage } \\
\hline No & 84,429 & $416(0.49)$ & 1.00 & 1.00 & 513,616 & $1008(0.20)$ & 1.00 & 1.00 \\
\hline Yes & 26,551 & $126(0.47)$ & $0.96(0.79-1.18)$ & $0.98(0.79-1.21)$ & 87,505 & $178(0.20)$ & $1.04(0.88-1.22)$ & $0.77(0.64-0.93)$ \\
\hline \multicolumn{9}{|l|}{ History on anemia } \\
\hline No & 109,641 & $516(0.47)$ & 1.00 & 1.00 & 593,758 & $1117(0.19)$ & 1.00 & 1.00 \\
\hline Yes & 1339 & $26(1.94)$ & $4.19(2.81-6.23)$ & $4.74(3.13-7.17)$ & 7363 & $69(0.94)$ & $5.02(3.93-6.41)$ & $6.33(4.89-8.20)$ \\
\hline \multicolumn{9}{|l|}{ Menstrual blood loss } \\
\hline Minor & 2497 & $7(0.28)$ & 1.00 & 1.00 & 17,536 & $29(0.17)$ & 1.00 & 1.00 \\
\hline Medium & 102,324 & $497(0.49)$ & $1.74(0.82-3.67)$ & $1.81(0.85-3.83)$ & 559,358 & $1092(0.20)$ & $1.18(0.82-1.71)$ & $1.20(0.83-1.74)$ \\
\hline Heavy & 5690 & $37(0.65)$ & $2.33(1.04-5.23)$ & $2.22(0.98-5.02)$ & 18,333 & $58(0.32)$ & $1.92(1.23-2.99)$ & $1.80(1.14-2.83)$ \\
\hline
\end{tabular}

a Adjusted for age, education, occupation, ethnic origin, residence of region, histories on pregnancy/miscarriage/anemia, menstrual blood loss/BMI/habit on eating meat and eggs. 
Analysis stratified by history of pregnancy was also performed. We found that women with a history of pregnancy had higher prevalence of severe anemia than women who were without such a history. Women aged 45-49 years had a higher risk of suffering severe anemia than other age groups, regardless of the history of pregnancy (Table 4). Furthermore, we conducted an analysis stratified by the number of pregnancies. The result showed that women with different pregnancy numbers had different prevalences of severe anemia. The prevalence was significantly different in 21-24, 25-29, and 30-34 year old age groups (Figure 2).

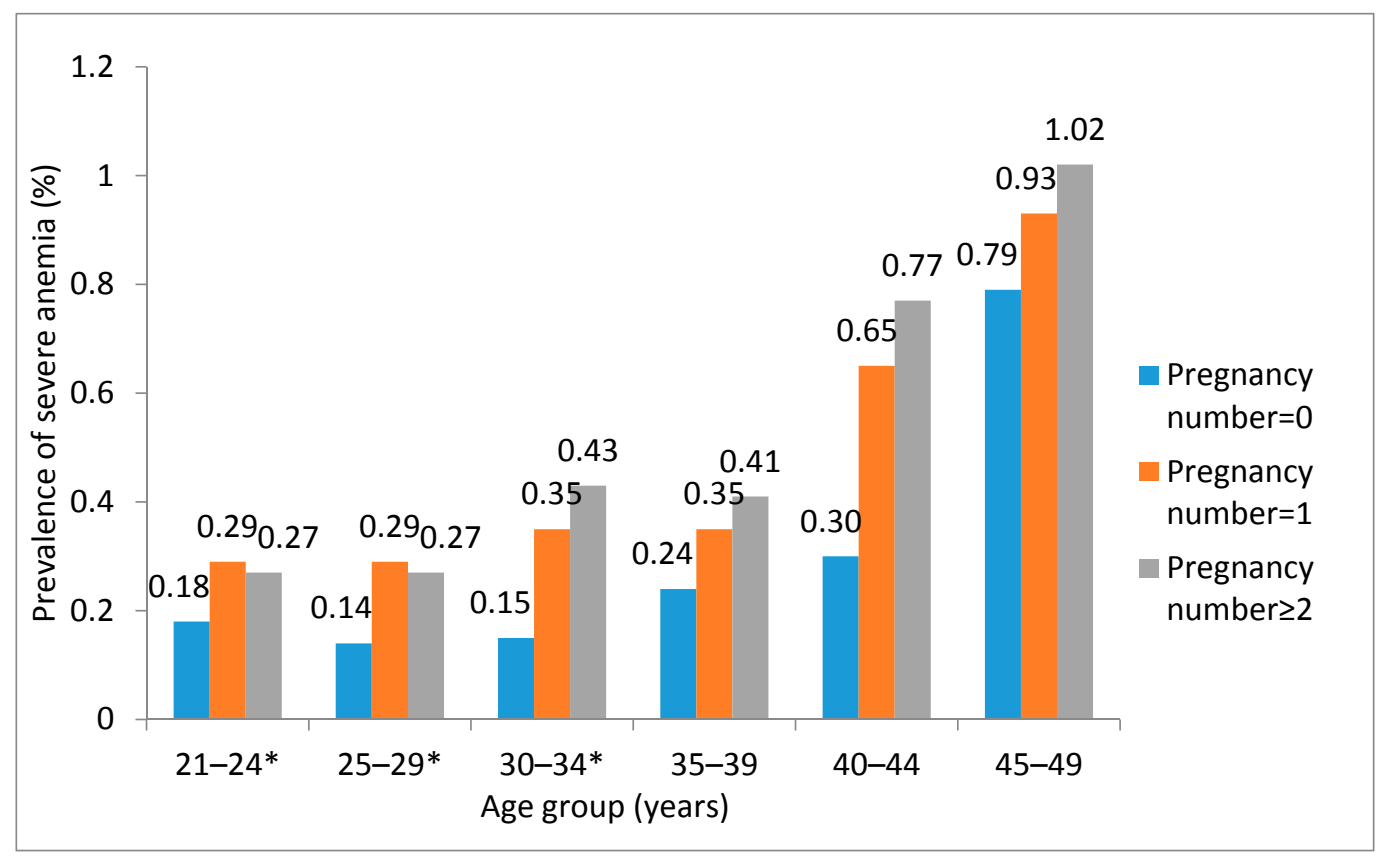

Figure 2. Age-specific prevalence rates of severe anemia in women with different pregnancy numbers in 2012, rural China. * The age group with significant difference in severe anemia prevalence in different pregnancy numbers. 
Table 4. Prevalence of severe anemia in different age groups among non-pregnant women of reproductive age, stratified by the history of pregnancy in 2012, rural China.

\begin{tabular}{|c|c|c|c|c|c|c|c|c|}
\hline \multirow{2}{*}{ Age Group, Years } & \multicolumn{4}{|c|}{ With Pregnancy History } & \multicolumn{4}{|c|}{ Without Pregnancy History } \\
\hline & Number & Severe Anemia, $n(\%)$ & cOR $(95 \% \mathrm{CI})$ & $\mathrm{aOR}^{\mathrm{a}}(95 \% \mathrm{CI})$ & Number & Severe Anemia, $n(\%)$ & cOR $(95 \% \mathrm{CI})$ & $\mathrm{aOR}^{\mathrm{a}}(95 \% \mathrm{CI})$ \\
\hline $21-24$ & 54,794 & $159(0.29)$ & 1.00 & 1.00 & 160,081 & $288(0.18)$ & 1.00 & 1.00 \\
\hline $25-29$ & 131,040 & $377(0.29)$ & $0.99(0.82-1.19)$ & $1.00(0.82-1.22)$ & 182,968 & $258(0.14)$ & $0.78(0.66-0.93)$ & $0.89(0.74-1.06)$ \\
\hline $30-34$ & 84,108 & $317(0.38)$ & $1.30(1.07-1.57)$ & $1.29(1.05-1.57)$ & 35,558 & $54(0.15)$ & $0.84(0.63-1.13)$ & $1.01(0.74-1.36)$ \\
\hline $35-39$ & 32,791 & $123(0.38)$ & $1.29(1.02-1.64)$ & $1.15(0.89-1.48)$ & 7218 & $17(0.24)$ & $1.31(0.80-2.14)$ & $1.15(0.66-2.01)$ \\
\hline $40-44$ & 13,798 & $95(0.69)$ & $2.38(1.85-3.07)$ & $2.39(1.83-3.12)$ & 2280 & $7(0.31)$ & $1.71(0.81-3.62)$ & $1.04(0.39-2.80)$ \\
\hline $45-49$ & 2658 & $25(0.94)$ & $3.26(2.14-4.98)$ & $3.06(1.96-4.80)$ & 492 & $4(0.81)$ & $4.55(1.69-12.25)$ & $5.05(1.86-13.66)$ \\
\hline
\end{tabular}

a Adjusted for education, occupation, ethnic origin, region, history of using IUD/miscarriage/anemia, menstrual blood loss/BMI/habits on eating meat and eggs. 


\section{Discussion}

Anemia in non-pregnant women is a global public health concern. In 2011, WHO reported that the global overall prevalence of severe anemia among non-pregnant women was $1.1 \%$, with the highest seen in Africa (1.6\%) and the lowest in Northern America (0.2\%) [1]. The prevalence of severe anemia among non-pregnant women in Asia was 1.3\% [1]. In our study, the prevalence of severe anemia prevalence appeared as $0.24 \%$ in Chinese non-pregnant women living in rural areas. This overall prevalence was lower than that reported in Asia and seemed consistent in China (0.3\%), as estimated by the WHO [1].

Previous studies noticed that demographic characteristics, such as age and levels of education, were associated with the prevalence of severe anemia [21,22]. An American study discovered that the rates on both anemia and moderate-severe anemia increased bimodally, with peaks seen in the 40-49 and 80-85 age groups [21]. Data from a study on anemia prevalence among Chinese non-pregnant women conducted in 11 provinces in 1998 discovered that the highest prevalence was seen among rural women aged 40-44 years (2.0\%) than from the other age groups (0.3-1.4\%) [18]. In our study, the result was similar with the above-mentioned study. We also noticed that the prevalence was higher in 40-49 year olds (0.63-0.92\%) than in other age groups (0.20-0.35\%). Our results indicated that older women of reproductive age had a higher risk of developing severe anemia.

Previous study also showed that the levels of education were related to healthcare seeking behavior [23], as well as the knowledge of nutrition of the women. Women are often responsible for producing and preparing food for the household, so their knowledge-or lack thereof-about nutrition can affect the health and nutritional status of the entire family [9]. Our study showed that the prevalence of severe anemia was seen as the highest among women with an education level of primary school or below, and appeared the lowest among women with an education level of college or higher. This result was consistent with previous studies [16,22,23]. Bentley et al. [16] reported a decreased risk of severe anemia among ever-married women with high school or higher education level in India. A study in Bangladesh reported that a lack of education was an important factor related to the prevalence of anemia among Bangladeshi women, and the authors believed that the increase in the education level would likely bring about a decline in the prevalence of anemia [22]. Wilunda et al. [23] found that primary school education reduced the risk of severe anemia by about $20 \%$, compared with those having no education at all.

In our study, the prevalence of severe anemia in farmers was significantly higher than in workers and other occupations, which might be related to the low socioeconomic status of farmers, and which represented insufficient diet, limited education, inadequate access to health services, and delayed diagnosis and treatment $[16,24]$ in this population. Meanwhile, farmers were exposed to occupational hazards, including extreme weather conditions, exposure to dangerous chemicals, schistosomiasis, and hookworm infections [5,24], which may lead them to suffer from severe anemia. The reduced work capacity caused by anemia was a burden on the rural Chinese women who were responsible for both domestic and field labor work. Low work capacity due to severe anemia often negatively affected household maintenance and income [5,25]. In different regions, the prevalence of severe anemia among women living in the northwest was the highest $(0.51 \%)$, while it was lowest among women in the central south $(0.15 \%)$. The geographic differences in severe anemia prevalence rates might correspond to the inequality of income and food availability in rural areas.

Histories on the use of contraceptive methods, reproduction, and health status were also associated with the prevalence of severe anemia. Approximately $50 \%$ of the anemic cases were considered to be related to iron deficiency [1]. Again, IUD use, menstrual blood loss, and pregnancy can cause extra iron loss in women. Iron deficiency anemia (IDA) arises when the body's loss of iron is insufficient to fully support red cell production [26]. We found that the prevalence of severe anemia in women who self-reported having a history of anemia was significantly higher than women without having the history on anemia $(\mathrm{OR}=5.76)$. This result indicated that anemic women who had not received 
effective prevention or treatment after the diagnosis was made usually ended up with a worsening status of anemia.

IUD are recognized as a modern effective contraceptive method, with less than $1 \%$ failure [27]. In China, a report in 2007 stated that there were 114 million women who use IUD, accounting for $49.79 \%$ of all the contraceptive methods being used [28]. The main side effect of IUD use was noted that it could increase the menstrual blood loss and IDA [29]. In our study, the risk of severe anemia among women with history of IUD use was 1.47 times higher than those without, and this trend was found similar in different age groups. Meanwhile, women aged $45-49$ years had a 2.90 times higher risk for severe anemia than those aged 21-24 years in the IUD-using group. Our findings indicated that women should take care of their own health status, especially for elder women, and choosing the IUD with caution.

Menstruation was an important factor which contributed to a negative iron balance in women [30]. We found that heavy menstrual blood loss was a determinant related to severe anemia in women at all ages. Stratified analysis on IUD use revealed that in women without the history of IUD use, heavy blood loss appeared as a determinant of severe anemia $(\mathrm{OR}=1.80)$. This finding indicated that blood loss should be highly concerned among women without the history of IUD use. In fact, every non-pregnant woman would lose $25-30 \mathrm{~mL}$ extra blood each month [2], which should prompt all women of reproductive age to monitor their iron status regularly.

Parity was found to be negatively associated with $\mathrm{Hb}$ concentration in previous study [31]. $\mathrm{Hb}$ concentration was noted to be lower in women with higher parity, which was a determinant for IDA. In our study, after adjusting the history of pregnancy to replace parity, data showed that the result was similar. The risk of severe anemia in women who had a history of pregnancy was 1.38 times to those who did not, and this trend was similar in different age groups. However, history of miscarriage did not seem to be a risk factor for severe anemia in women with a history of using an IUD, but appeared as a protective factor for women without such a history. This result suggested that the association between miscarriage and severe anemia requires further study.

Compared with non-heme iron, absorption of heme iron does not require binding proteins [32], so its uptake is easy for human beings. For non-vegetarians, heme iron, especially those from red meat, such as beef and lamb, contribute at least $40 \%$ of the total iron absorbed [33]. Therefore, women living in the rural areas of China who consume mostly grains and vegetables would absorb less iron from their diet. However, we did not find that the habit of eating meat and eggs was a factor associated with severe anemia, with the postulation that severe anemia was mostly related to the decrease of red cell production [5]. Less iron intake from the diet might lead to mild, rather than severe, anemia. Additionally, there were few women who were not meat and egg eaters (1.04\%) in our study, which might interfere with the results.

To our knowledge, this study was the largest population-based one on severe anemia that focused on non-pregnant women in rural China. Prior to our study, there were only two surveys regarding national nutrition status, conducted in 2002 and 2010 [34,35] that mentioned the overall prevalence on anemia rather than on severe anemia, among women of reproductive age. A small sample-sized study is difficult to assess the prevalence of severe anemia, which is a rare disease in nature. The sample size of our study was large enough to have covered 30 provinces, 193 counties of China, with a total population size as large as 712,101. The definition of severe anemia was under the criteria set by WHO, enabling our result to compare with other study of the same kind.

Limitations in our study include the following: the inclusion of our sample only involved women who were not pregnant, but planned to get pregnant in six months, from rural China, leaving the prevalence not representative for all women of reproductive age in the country. There were few severe anemia cases in some subgroups, which was a limitation for the results we reported. Data regarding time was not mentioned on IUD use and histories of pregnancy or miscarriage, which limited the interpretation of the association between severe anemia and these factors. There was potential bias due to the inclusion of anemia caused by specific etiology, such as genetic disorders. 


\section{Conclusions}

In conclusion, the prevalence of severe anemia among non-pregnant women living in rural areas in China was lower than the global prevalence, despite the fact that it was seen as higher in some particular groups. Women who were elderly, living in the northwest region, with low education levels, being farmers, having had histories of anemia or ever using IUD, and with heavy menstrual blood loss, etc., were under higher risk for severe anemia. With the limited medical resources in rural areas, women with higher risk of severe anemia should have priority to be paid close attention. Effective strategies on prevention and management of anemia in non-pregnant women can improve the health status of these women prior to, or during, pregnancy, eventually contributing to the reduction on adverse pregnancy outcomes, and maternal and perinatal mortality.

Acknowledgments: This research was supported by the Chinese Association of Maternal and Child Health Studies (AMCHS-2014-6). The funder had no role in study design, data collection, data analysis, data interpretation, or writing of the report. The corresponding author had access to all data in the study and had final responsibility for the decision to submit for publication. The views expressed in the report are those of the authors and do not necessarily reflect the official policy or position of the Department of Maternal and Child Health of National Health and Family Planning Commission in China. We thank all the health workers in 193 counties for their strong collaboration and great effects made in the NFPHEP.

Author Contributions: Q.M. and S.Z. searched the literature, designed the study, analyzed the data, interpreted the results, and drafted the manuscript. J.L., Q.W., H.S. and Y.Z. collected the data and revised the manuscript. M.L. conceived the study, designed the study, supervised the study, interpreted the results, and revised the manuscript. Q.M. and S.Z. made same contribution to this paper. All authors contributed to the writing of the manuscript.

Conflicts of Interest: The authors declare no conflict of interest.

\section{References}

1. World Health Organization (WHO). The Global Prevalence of Anaemia in 2011; World Health Organization: Geneva, Switzerland, 2015.

2. World Health Organization (WHO). The Prevalence of Anaemia in Women: A Tabulation of Available Information; World Health Organization: Geneva, Switzerland, 1992.

3. Alem, M.; Enawgaw, B.; Gelaw, A.; Kenaw, T.; Seid, M.; Olkeba, Y. Prevalence of anemia and associated risk factors among pregnant women attending antenatal care in Azezo Health Center Gondar town, Northwest Ethiopia. J. Interdiscip. Histopathol. 2013, 1, 137-144. [CrossRef]

4. Balarajan, Y.; Ramakrishnan, U.; Ozaltin, E.; Shankar, A.H.; Subramanian, S.V. Anaemia in low-income and middle-income countries. Lancet 2011, 378, 2123-2135. [CrossRef]

5. Adamu, A.L.; Crampin, A.; Kayuni, N.; Amberbir, A.; Koole, O.; Phiri, A.; Nyirenda, M.; Fine, P. Prevalence and risk factors for anemia severity and type in Malawian men and women: Urban and rural differences. Popul. Health Metr. 2017, 15, 12. [CrossRef] [PubMed]

6. Kassebaum, N.J.; Jasrasaria, R.; Naghavi, M.; Wulf, S.K.; Johns, N.; Lozano, R.; Regan, M.; Weatherall, D.; Chou, D.P.; Eisele, T.P.; et al. A systematic analysis of global anemia burden from 1990 to 2010. Blood 2014, 123, 615-624. [CrossRef] [PubMed]

7. Toteja, G.S.; Singh, P.; Dhillon, B.S.; Saxena, B.N.; Ahmed, F.U.; Singh, R.P.; Prakash, B.; Vijayaraghavan, K.; Singh, Y.; Rauf, A.; et al. Prevalence of anemia among pregnant women and adolescent girls in 16 districts of India. Food Nutr. Bull. 2006, 27, 311-315. [CrossRef] [PubMed]

8. Hashim, N.; Farooqi, M.; Naqvi, S.; Jaffery, H.F. Anemia; moderate to severe during pregnancy. Prof. Med. J. 2014, 21, 247-252.

9. Ransom, E.I.; Elder, L.K. Nutrition of Women and Adolescent Girls: Why It Matters; Population Reference Bureau: Washington, DC, USA, 2003.

10. Rahmati, S.; Delpisheh, A.; Parizad, N.; Sayehmiri, K. Maternal anemia and pregnancy outcomes: A systematic review and meta-analysis. Int. J. Pediatr. 2016, 4, 3323-3342.

11. Lone, F.W.; Qureshi, R.N.; Emanuel, F. Maternal anaemia and its impact on perinatal outcome. Trop Med. Int. Health 2004, 9, 486-490. [CrossRef] [PubMed] 
12. Gomes da Costa, A.; Vargas, S.; Clode, N.; Graça, L.M. Prevalence and risk factors for iron deficiency anemia and iron depletion during pregnancy: A prospective study. Acta Med. Port. 2016, 29, 514-518. [CrossRef] [PubMed]

13. Stevens, G.A.; Finucane, M.M.; De-Regil, L.M.; Paciorek, C.J.; Flaxman, S.R.; Branca, F.; Peña-Rosas, J.P.; Bhutta, Z.A.; Ezzati, M.; Nutrition Impact Model Study Group. Global, regional, and national trends in haemoglobin concentration and prevalence of total and severe anaemia in children and pregnant and non-pregnant women for 1995-2011: A systematic analysis of population-representative data. Lancet Glob. Health 2013, 1, e16-e25. [CrossRef]

14. Chang, S.C.; O’Brien, K.O.; Nathanson, M.S.; Mancini, J.; Witter, F.R. Hemoglobin concentrations influence birth outcomes in pregnant African-American adolescents. J. Nutr. 2003, 133, 2348-2355. [PubMed]

15. Sharma, P.; Mehta, S.; Nagar, R. Prevalence of anemia and socio-demographic factors associated with anemia among pregnant women attending antenatal Hospital in Jaipur City, India. IOSR J. Pharm. Biol. Sci. 2013, $6,1-5$.

16. Bentley, M.E.; Griffiths, P.L. The burden of anemia among women in India. Eur. J. Clin. Nutr. 2003, 57, 52-60. [CrossRef] [PubMed]

17. World Health Organization (WHO). Haemoglobin Concentrations for the Diagnosis of Anaemia and Assessment of Severity; World Health Organization: Geneva, Switzerland, 2011.

18. Capital Institute of Pediatrics, 11 Provinces Maternal Child Health Hospital. Survey of women anaemia status at child-bearing age in China in 1998. Chin. J. Reprod. Health 2002, 13, 102-107.

19. Zhang, S.K.; Wang, Q.M.; Shen, H.P. Design of the National Free Preconception Health Examination Project in China. Chin. Med. J. 2015, 95, 162-165. [CrossRef]

20. Wang, Q.M.; Zhang, S.K.; Hu, M.; Kang, X.X. Establishment of quality assurance system of the National Free Preconception Health Examination Project in China. Chin. Med. J. 2015, 95, 166-168. [CrossRef]

21. Le, C.H.H. The prevalence of anemia and moderate-severe anemia in the US population (NHANES 2003-2012). PLoS ONE 2016, 11, e0166635. [CrossRef] [PubMed]

22. Kamruzzaman, M.; Rabbani, M.G.; Saw, A.; Sayem, A.; Hossain, G. Differentials in the prevalence of anemia among non-pregnant, ever-married women in Bangladesh: Multilevel logistic regression analysis of data from the 2011 Bangladesh Demographic and Health Survey. BMC Womens Health 2015, 15, 54. [CrossRef] [PubMed]

23. Wilunda, C.; Massawe, S.; Jackson, C. Determinants of moderate-to-severe anaemia among women of reproductive age in Tanzania: Analysis of data from the 2010 Tanzania Demographic and Health Survey. Trop Med. Int. Health 2013, 18, 1488-1497. [CrossRef] [PubMed]

24. Moor, M.A.; Fraga, M.A.; Garfein, R.S.; Harbertson, J.; Rodriguez-Lainz, A.; Rashidi, H.H.; Elder, J.P.; Brodine, S.K. Decreased anemia prevalence among women and children in Rural Baja California, Mexico: A 6-year comparative study. J. Community Health 2016, 41, 780-789. [CrossRef] [PubMed]

25. Haas, J.D.; Brownlie, T. Iron deficiency and reduced work capacity: A critical review of the research to determine a causal relationship. J. Nutr. 2001, 131, 676S-690S. [PubMed]

26. Miller, J.L. Iron deficiency anemia: A common and curable disease. Cold Spring Harb. Perspect. Med. 2013, 3, a011866. [CrossRef] [PubMed]

27. Behboudi-Gandevani, S.; Imani, S.; Moghaddam-Banaem, L.; Roudbar-Mohammadi, S. Can intrauterine contraceptive devices lead to VulvoVaginal Candidiasis (VVC) and Anemia in Iranian new users? Sex. Reprod. Healthc. 2015, 6, 40-43. [CrossRef] [PubMed]

28. National Health and Family Planning Commission of the PRC. Report of investigation on the contraception effect of intrauterine device by one hundred and twenty thousand cases. Chin. J. Family Plan. 2007, 15, 132-136. [CrossRef]

29. Borghei, A.; Qorbani, M.; Borghei, N.S.; Kazeminejad, V.; Seifi, F. Effects of IUD on iron status in IUD users in Gorgan, Iran. Med. J. Islam. Repub. Iran 2011, 25, 131-135.

30. Blanco-Rojo, R.; Toxqui, L.; Lopez-Parra, A.M.; Arroyo-Pardo, E.; Vaquero, M.P. Influence of diet, menstruation and genetic factors on iron status: A cross-sectional study in Spanish women of childbearing age. Int. J. Mol. Sci. 2014, 15, 4077-4087. [CrossRef] [PubMed] 
31. Karakochuk, C.D.; Whitfield, K.C.; Barr, S.I.; Lamers, Y.; Devlin, A.M.; Vercauteren, S.M.; Kroeun, H.; Talukder, A.; McLean, J.; Green, T.J. Genetic hemoglobin disorders rather than iron deficiency are a major predictor of hemoglobin concentration in women of reproductive age in rural prey Veng, Cambodia. J. Nutr. 2015, 145, 134-142. [CrossRef] [PubMed]

32. Alaunyte, I.; Stojceska, V.; Plunkett, A. Iron and the female athlete: A review of dietary treatment methods for improving iron status and exercise performance. J. Int. Soc. Sports Nutr. 2015, 12, 38. [CrossRef] [PubMed]

33. Harvey, L.J.; Armah, C.N.; Dainty, J.R.; Foxall, R.J.; John Lewis, D.; Langford, N.J.; Fairweather-Tait, S.J. Impact of menstrual blood loss and diet on iron deficiency among women in the UK. Br. J. Nutr. 2005, 94, 557-564. [CrossRef] [PubMed]

34. Li, L.M.; Rao, K.Q.; Kong, L.Z.; Yao, C.H.; Xiang, H.D.; Zhai, F.Y.; Ma, G.S.; Yang, X.G.; Technical Working Group of China National Nutrition and Health Survey. A description on the Chinese national nutrition and health survey in 2002. Chin. J. Epidemiol. 2005, 26, 478-484. [CrossRef]

35. Hu, Y.C.; Chen, J.; Li, M.; Li, W.; Yang, Y.; Wang, R.; Piao, J. Study on the anemia status of Chinese urban residents in 2010-2012. Chin. J. Prev. Med. 2016, 50, 213-216. [CrossRef]

(C) 2017 by the authors. Licensee MDPI, Basel, Switzerland. This article is an open access article distributed under the terms and conditions of the Creative Commons Attribution (CC BY) license (http://creativecommons.org/licenses/by/4.0/). 